\title{
Magic Numbers and Golden Rules
}

\author{
MARGARET LAW AND PAULA BEEVER \\ Arup Fire \\ Ove Arup and Partners \\ 13 Fitzroy Street \\ London W1P $6 B 0$
}

\begin{abstract}
The application of fire safety research using engineering methods is frustrated by conventional attitudes. The desire of researchers to always achieve a greater level of understanding means that they cannot recognise that satisfactory engineering solutions may be achieved with partial information. The desire of regulators to have simple rules and tests for administrative convenience contrasts with the need of designers to have maximum flexibility in order to arrive at optimum solutions. The magic numbers embodied in regulations are accepted without question whilst any engineering solution is subject to a disproportionately high standard of proof. To move forward, rules need to have an engineering basis and to be goal related: the purpose of the rules needs to be understood by both researchers and regulators.
\end{abstract}

\section{INTRODUCTION}

The value of this scientific conference is that it provides not only a forum for the exchange of information but also an opportunity for the exchange of ideas. Indeed we understand that several new lines of research were conceived directly as a result of discussions at earlier IAFSS conferences. We, as practitioners, would also like to exchange ideas with scientists, and it is the purpose of this paper to stimulate similar discussions.

During the closing sessions of most fire research conferences there is a plea for more contributions from the practitioners - the consultants and the fire service - and there is normally a murmur of agreement to this from the audience. At the next conference, therefore, a token consultant and a token fire officer will each present a paper. From long experience as token consultants we know that any such paper will attract virtually no comment or there will be a trivial question which shows that the concepts have been misunderstood or ignored. It can be argued, of course, that the papers were badly written, but it is our view that many researchers are not interested in applications, that is how designers and firemen solve practical problems, or they are interested in only a very narrow field of fire engineering.

Not all researchers need to be interested in applications, but we believe that for many of us it would be beneficial if we could have a better understanding of each other's work. Therefore in this paper we are going to share some of our ideas and experiences and at times we will aim to be provocative. 


\section{SIMPLE SOLUTIONS NOT SIMPLE RULES}

In general, the results of fire research will be applied in one or more of the following ways: product development; tests for products; regulations and design codes.

Manufacturers can sell only those products which pass the tests and follow the rules. Unfortunately, the existing tests and regulations can prevent the application of good research because they are presented in a very simple way: Class 1,2 or 3 for a material, or $45 \mathrm{~m}$ escape distance, for example. This approach is perceived by the regulators to have two major benefits: firstly that it makes it easy for them to check that projects comply with the rules and secondly that engineers and architects only want to have simple rules. Both these assumptions are wrong.

When there are simple and arbitrary rules there are always more arguments and disputes than when an engineering approach is adopted, because the underlying technical assumptions are forgotten or not understood. When researchers reduce their results to a few 'golden' rules, they misunderstand the engineering design process. Engineers and architects do not set out to make life easy for themselves: they do not in fact seek simple rules. The designer aims for simplicity, reliability, quality and fitness for purpose in the end product be it a hotel or an offshore oil platform. The contribution of fire safety design to this process is no different from any other kind of design. A project must proceed subject to all kinds of constraints of which fire safety is one, but financial, traditional and political considerations may be just as influential. Good design will seek to harmonise conflicts and optimise outcomes, and this can better be achieved if designers are given the opportunity to make fullest use of the tools and data available.

Of course, there will always be a place for prescriptive standards: there should be a straightforward route for straightforward design. But let us not pretend that if these standards are applied they will always, in some magic way, give the best solution. As soon as they frustrate design we should be able to re-establish the rationale behind the rules and thereby develop new approaches.

\section{REGULATORS AND THE BABY-IN-THE-BUICK EFFECT}

There has been a considerable improvement in recent years in the response of many regulatory authorities to fire safety proposals based on engineering analysis rather than on regulatory compliance. Indeed, in some industries such as oil and chemicals, such approaches are rapidly becoming the norm. However, there is still an almost universal failure on the part of the authorities to grasp the significance of what is being presented to them.

A common misconception is that the role of the fire safety engineer is to predict in detail what will happen in the event of a fire. This is not the case. The fire safety engineer must produce a design which achieves adequate safety levels. In demonstrating this, the engineer may make use of some predictive techniques. But, perhaps surprisingly, these do not need to be precise or comprehensive in every instance. A small departure from a coded requirement does not place upon the engineer the task of carrying out a full fire safety analysis. We find that the regulators behave as though it does. 
One reason for this is that regulatory authorities are comfortable with their magic numbers. If the distance to a door is no more than $45 \mathrm{~m}$, the building is safe. They need to think no further. But what if the distance happens to be $50 \mathrm{~m}$ ? Clearly a moderate improvement in some other fire safety feature of the building should quite easily compensate for the additional time required for people to travel the extra few metres. However, under such circumstances the fire safety engineer is frequently required to provide design fire specifications, smoke filling calculations, evacuation analysis and so forth even though a building designed to the magic numbers could not bear such rigorous analysis. The regulating authority may further assume the right to choose the fire scenario which is the basis for the design, regardless of how unlikely this might be. There can be endless "what if" questions and the fire safety issues can entirely dominate in what becomes an unbounded problem.

A simple, if absurd, example is as follows:

The standard fire resistance test gives a reasonable representation of the heat transfer inside a compartment containing a post-flashover fully developed fire, and we know that after flashover people inside the compartment will not survive. When it was demonstrated in a particular instance that the fire loading in car parks was low and that it was unlikely that fire in one car would spread to another, regulators opposed any reduction in fire resistance on the grounds that "people leave their babies in the car while they go shopping." Quite apart from the fact that there was no evidence that people left their babies in this way, the argument was obviously absurd.

Nevertheless, the regulators considered that, in some magic way, the existing rules would protect the baby.

Current moves towards risk analysis in fire safety engineering may ultimately relieve us of this kind of arbitrary approach. In the meantime we are left to struggle in a system which tends to be strongly biassed against rational analysis.

The fact that total predictive capability is not needed by the fire safety engineer means that good use can be made of raw or incomplete research data. Information gathered for one purpose can be used for another. What is vital is that the information should be gathered in a scientific manner, published openly, and subject to peer review.

\section{RESEARCH, INVESTIGATION AND THE RATCHET EFFECT}

It might appear that the regulators are largely to blame for the failure to propagate the results of good research, but the researchers themselves are often at fault to a degree. Research is conducted in an environment where identifying the questions and posing solutions is conducted in a necessarily constrained manner. The emphasis is on obtaining an understanding, ideally with predictive capability, in a particular field by successively refining the questions which can be resolved. The researcher is therefore more acutely focused on what is not known than of the value of the knowledge which has been accumulated. A quite healthy but rather obstructive scepticism therefore may overlie the researcher's attitude to the use of the results in practice. 
As a result, the transfer of technology from the researcher to the real world is subject to a bias in the form of a ratchet mechanism. Because fire research is almost entirely bound up with safety issues, and there is very little conducted on a purely fundamental level, there is an inherent prejudice in favour of releasing and applying results at the earliest stage if lives can thereby be saved. Thus if a researcher identifies a powerful toxin which could be given off by burning a particular material, this research is likely to be taken up rapidly and applied at an early stage in regulations. This may be contrasted with research carried out which shows that the current approaches to fire safety may be over restrictive. There is likely to be a very sluggish and more cautious take up of such research, with considerably more effort being made to verify any conclusions before the regulators feel they can take advantage of any benefits. An example of this would be in the field of sprinklers and fire. The evidence is considerable from a number of sources to suggest that sprinklered buildings are extremely safe from fire. It has even been suggested that a well designed sprinkler system with a very high level of reliability could be defensibly installed as the only fire safety measure in a building. This type of radical approach would clearly take a long time to be accepted, but even at present, the relaxations in fire safety measures for sprinklered buildings rarely reflect the high degree of enhanced safety. In some countries no relaxation of traditional fire safety measures is permitted at all.

The other ratchet which serves to increase fire safety provisions rather than otherwise is the rare but significant occurrence of major fires. Public attention is attracted quite rightly to any kind of tragedy which causes multiple deaths. Public tolerance of such incidents is low even where on a statistical basis the risk to any individual of becoming involved in such an event may be extremely small. As a result, major fires are the subject of intensive investigation and analysis.

The outcome of such studies is generally to identify the major contributory factors which led to the incident becoming as serious as it did. The investigation is likely to be conducted on several levels concerned with details of the initiation of and communication about the event, the behaviour of survivors, victims and firefighters, and theoretical and possibly experimental studies of fire and smoke behaviour. The results of all of these studies are likely to emerge as a set of recommendations for improvements in an attempt to ensure that such an incident could not be repeated. The problem is that the results are unlikely to be formulated as a series of alternatives, the implementation of any one of which would have avoided the tragedy, but rather as a set of measures which must be adopted as a whole. This approach, whilst very well intentioned, leads to new sets of golden rules because of a failure of rational analysis.

\section{RESEARCH AND TECHNOLOGY TRANSFER: FORM FOLLOWS FUNCTION}

In our view, the simple and complete description of "fire protection engineering" is that it is the application of science and engineering principles to protect man and his environment from destructive fire ${ }^{[i]}$. The very least we expect from researchers and practitioners is that they are scientific. This may sound obvious, but in practice we use various paradigms, that is we assume patterns of behaviour for the purpose of planning experiments and analysing the results, and also for engineering design. Such paradigms are extremely useful but need to be replaced or reviewed in the long term if they are not to get in the way of scientific analysis. One example is the use of visibility to define tenable smoke conditions, when it is actually narcotic substances and heat which kills people, not loss of visibility. Another is the use in design of the 
t-equivalent formula for a compartment fire, when the correct procedure is to estimate the temperature and duration of the fire directly.

The transfer of research and technology to practical guidance for engineers usually requires a great deal of effort in order to avoid misinterpretation and misapplication. It has at least three stages: selection and/or production of research results; analysis of these results and their relevance to the subject under consideration; preparation of a design manual. All these stages need to be published so that as circumstances and knowledge change, the guidance can be reviewed. Some examples of this approach are: the guidance on roof-venting of single storey factories, prepared by researchers, financed by a manufacturer of roof vents; $;^{[2 ; 3]}$ guidance on the fire safety of exposed exterior structural steel, prepared by consultants, financed by the steel industry ${ }^{[4] / 5]}$ guidance on the location of television towers in relation to buildings and prevention of spread of fire from floor to floor of a building via the window openings, prepared by a researcher, financed by Government $t^{[6]}$. None of these documents give golden rules such as "vents should be $5 \%$ of the floor area" or "bare steel should be $1.5 \mathrm{~m}$ distant from the windows". They give practical engineering relationships.

Another valuable method of transferring research is in the form of codes of good practice. In our experience the fire engineering codes of practice suffer because the statements of what they are intended to achieve are either imprecise or missing altogether. There is merit in examining how codes of practice are prepared in other engineering disciplines.

As part of the removal of barriers to trade within Europe, structural Eurocodes have been prepared. These have had to be written very formally. For example: the principle has to be stated before a rule can be given; no commentary is allowed (although an explanatory note may be permitted); nothing is to be included which is already in another code. This formality forces the code authors to state in a consistent way what it is they are trying to achieve: a very difficult task. If they do the job properly, it is in principle possible for an engineer to read the set of principles and rules and design accordingly. In practice application manuals are being prepared. No doubt these manuals will have their quota of magic numbers and golden rules, but at least the underlying assumptions will be those in the formal code. In our view it would be a good discipline for our fire code writers to write a formal code. What we are saying is that form follows function: you decide what it is you want to do before you decide what tools you are going to use.

\section{CONCLUDING REMARKS}

From a global point of view, the prescriptive approach may produce the desired results: the total losses by fire, year on year, are kept below a certain level. Yet it is obvious that, even if all projects comply with the codes, they are not all equally safe. A change to engineering-based rules will give more uniform results but there will still be significant variations between projects. For any specific project, the fire engineer will have to use judgement in addition to rules, as would any other engineer, to satisfy the search for adequate safety. The judgement will take into account the other aspects of engineering design and the way the project will be operated, so that fire considerations can be set in context.

Information and data about fire behaviour will assist judgement. For this reason it is important that research information is not processed and subjected to the researcher's bias before it is published for the designer's use. 
Secondly, we want the researchers to be viewing each problem as if it were fresh. Practitioners and regulators may feel comfortable with the old rules but researchers should not.

Thirdly, when researchers are asked to devise a test or formulate a rule they should first establish, in concert with the regulators, what it is they are trying to achieve. This should then be written down as a basis for what follows. When it is difficult to do this it would be better to delay the test or rule, since once it is published it is very difficult to get rid of it.

Lastly, we appeal for a rational approach to the regulation of fire safety design, which is goal related rather than disaster driven, which encourages flexibility and imagination, and which uncovers opportunities which can be fed back into research programmes.

\section{REFERENCES}

1. Society of Fire Protection Engineers

2. Thomas, P.H. et al. Investigation into the flow of hot gases in roof venting Fire Research Technical Paper No. 7. London: HMSO 1963.

3. Thomas, P.H. and Hinkley, P.L. Design of roof-venting systems for single storey buildings. Fire Research Technical Paper No. 10. London: HMSO 1964.

4. Law, Margaret. "Fire safety of external building elements - the design approach". Engineering, Second Quarter 1978. American Inst. of Steel Constr., New York.

5. Fire-safe structural steel. A design guide. American Iron and Steel Inst., Washington D.C. 1977.

6. Yokoi, S. Study on the prevention of fire-spread caused by hot upward current. Japanese Ministry of Construction Building Research Institute Report No. 34. Tokyo Nov. 1969. 